\title{
Assessment of Serum Vitamin D3 Level in One Year Old Children Using D3 Supplement
}

Danial Alebouyeh

Student Research Committee

Nasrin Khalessi

Department of Neonatology

Maryam Saboute (D Saboutem@yahoo.com )

shahid akbarabadi clinical research development unit https://orcid.org/0000-0003-2146-3752

Maryam Alizadeh Chamkhaleh

Student Research Committee

Mandana Kashaki

Shahid Akbarabadi Clinical Research Development Unit

\section{Research}

Keywords: Vitamin D3, Infant, Supplement

Posted Date: August 18th, 2020

DOI: https://doi.org/10.21203/rs.3.rs-55450/v1

License: (c) (1) This work is licensed under a Creative Commons Attribution 4.0 International License. Read Full License 


\section{Abstract}

Introduction. Vitamin D status is a key determinant of bone health and growth during childhood and adolescence. Therefore, we design a study to find out the association between the levels of serum vitamin $\mathrm{D}$ and need to consumption of vitamin $\mathrm{D}$ supplement.

Method and materials. In this cross sectional study infants under 20 months referred to Ali Asghar Children's Hospital were included. Infants with maternal diseases and congenital malformations were excluded. All infants used vitamin D3 supplementation $400 \mathrm{IU}$ per day from day fifth of birth. The level of 25-hydroxy vitamin $D$ at the age of 1 years (month 12) were measured. Level of 25-hydroxy vitamin $D$ in mothers were checked, too. Furthermore, we defined sufficient level of 25 -hydroxy vitamin $D \geq 30 \mathrm{ng} / \mathrm{ml}$.

Results. In this study, 68 infants under 20 months were examined. Half of them were boy. Mean age of infants was $16 \pm 3$ months and mothers was $33 \pm 3$ years old. In addition, the mean level of serum 25 hydroxy vitamin $D$ in the infants were $40.99 \pm 13.86 \mathrm{ng} / \mathrm{ml}$ and in mothers were $31.39 \pm 13.14 \mathrm{ng} / \mathrm{ml} .62 .1 \%$ of mothers were in sufficient group and also $83 \%$ of infants had sufficient vitamin D level (25-hydroxy vitamin $D \geq 30 \mathrm{ng} / \mathrm{ml}$ ). There was not any significant correlation between vitamin $D$ level in infants and mothers $(P$ value $=0.965)$. The mean level of serum vitamin $D 3$ in boys was $39.55 \pm 3.79 \mathrm{ng} / \mathrm{ml}(12-51)$ and girls was $35.32 \pm 3.67 \mathrm{ng} / \mathrm{ml}$ (13.4-50). Similarly, significant relationship was not shown between gender and vitamin $D$ of infants ( $P$ value $=0.437$ ). Level of vitamin $D$ in second children was significantly higher than first children $(P$ value $=0.011)$. The correlation between gestational age and vitamin $D 3$ deficiency was also insignificant $(P$ value $=0.087)$. Head circumference $(r=-0.404, P$ value $=0.014)$ and age of mothers $(r=0.344, P$ value $=0.04)$ correlated with vitamin $D$.

Conclusion. In summary, we demonstrated most of the infants had sufficient vitamin D level at the age of 1 year. So it is recommended to continue vitamin D3 supplementation consumption.

\section{Introduction}

One of the important and useful substance for having healthy bones is vitamin D. We need sunlight and good renal and liver function to synthesize vitamin $D$, although it can also be gained from diet. Rickets and osteomalacia are related diseases that occur when person have severe deficiency pf this vitamin (1). Due to different reasons, osteopenia of Prematurity is common in premature infants (2).

Vitamin D has some other benefit for body which is implication in function of muscles in both children and adults (3). Non-vertebral fractures can also be prevented with Supplementation of vitamin D (1).

People in the parts of Asia and Middle East experience inadequate sunshine and also low vitamin D intake. Therefore it causes severe vitamin D deficiency in mothers and their breastfed infants which is a significant health problem (4-6). 
In addition, vitamin $D$ deficiency is widespread in the neonatal and pediatric population of northern latitudes, particularly in children of African, Middle Eastern and Asian ethnicity (7).

Discrepancies in the findings could be attributed, to the differences in ethnicity, amount of vitamin D supplementation, geographical locations and duration of using supplementation. It is recommended infants who are exclusively breastfed take $400 \mathrm{IU}$ of vitamin D supplementation daily, when sunshine exposure is low or maternal vitamin $D$ status is judged to be inadequate (8). All the current recommendations of using vitamin $D$ are based on bone health. $97.5 \%$ of the population requires an intake below this recommended amount (9).

According to one trial there is a recommendation for consuming vitamin $D$ supplementation in low birth weight term infants. When infants from 1 week to 6 months of age use this supplementation resulted in increased length and weight at 6 months (10).

Thus, optimizing vitamin $\mathrm{D}$ status could be one of the cornerstones to optimize skeletal growth and achieving the maximum peak bone mass soon after the completion of adolescence. Maximizing peak bone mass is considered to be the key to primary prevention of osteoporosis (11). Besides these information, the long-term effects of infant vitamin $D$ supplementation and status are unclear since there have been few controlled intervention trials and these have been small and contradictory.

According to various studies, the use of vitamin $D$ is necessary for infants and mothers but there are some different and contradictory opinions about using vitamin D supplement. Therefore, due to the probable relationship between the deficiency of serum vitamin D3 and some complications, we designed a study to find out the association between the level of serum vitamin D3 and need to consumption of vitamin D3 supplement in neonates. Then we can safely use this supplement for them. In addition, we clarify that consuming vitamin D $400 \mathrm{mg}$ from birth is enough for neonates or not.

\section{Method And Materials}

This cross-sectional study consists of 68 infants under 20 months referred to Ali Asghar Children's Hospital.

Infants were examined at the age of months 12 and were checked for vitamin D3 level. We recalled all demographic information of infants and mothers. Age, sex, gestational age, season of birth, birth weight and head circumference were asked from parents. Also level of vitamin D3 in infant and mother at months 12 after delivery were collected.

All infants used vitamin D supplementation 400 IU per day. Infants with maternal diseases and congenital malformations were excluded.

Furthermore, the amount of Vitamin D3 levels divided in to two levels which are sufficient and deficient group. The amount more than $30 \mathrm{ng} / \mathrm{ml}$ considered sufficient in both infants and mothers (12). 
In all steps carried out in this study, the principles of the Declaration of Helsinki (ethical principles for medical research involving human subjects) and the Ethics Committee of Iran University were followed. The study was approved by Iran University's Ethics Committee.

\section{Data analysis}

Statistical analysis was done using SPSS software (statistical product and service solutions, version 20.0. SPSS Inc., Chicago, IL, USA). Data were summarized as Mean \pm SE (standard error of the mean). Kolmogorov-Smirnov test was conducted to observe the distribution of parameters in the study groups. Continuous two independent groups were compared by Student's t test or Mann Whitney U test. Continuous more than 2 independent groups were compared by one way analysis of variance (ANOVA), Categorical (discrete) groups were compared by Chi square $(\chi 2)$ test. Pearson correlation analysis was done to assess association between the variables. Statistical significance was set on a $p$-value lower than 0.05 .

\section{Results}

In this study, 68 infants under 20 months were examined. Half of them were boy. The age of participants was in the range of 12 to 23 months. The mean age of infants was $16 \pm 3$ months and mothers was $33 \pm$ 3 years old. Demographic information of infants and mothers are shown in Table 1.

According to season of birth $34 \%$ of infants born in winter, $28 \%$ in autumn, $26 \%$ in summer and $12 \%$ in spring. In addition, 34 infants were first child and 16 were second one.

There was not significant correlation between vitamin D3 level in infants and mothers ( $P$ value $=0.965)$.

$62.1 \%$ of mothers were in sufficient group and $83.3 \%$ of infants had sufficient vitamin D, too. (25-hydroxy vitamin $\mathrm{D} \geq 30 \mathrm{ng} / \mathrm{ml}$ ). (Table 2).

Difference between the level of vitamin $D$ in boys and girls was insignificant ( $P$ value $=0.437$ ). The mean level of serum vitamin D3 in boys was $39.55 \pm 3.79 \mathrm{ng} / \mathrm{ml}(12-51)$ and girls was $35.32 \pm 3.67 \mathrm{ng} / \mathrm{ml}$ (13.4-50). Moreover, there is not any differences between boys and girls in each group of vitamin $D$ range $(P$ value: Sufficient $=0.11$, Deficient $=0.64$ )

In addition the mean level of serum vitamin $D$ in first children was $35.91 \pm 3.33 \mathrm{ng} / \mathrm{ml}(12-50)$ and in second children was $42.18 \pm 3.50 \mathrm{ng} / \mathrm{ml}(27-51)$. Differences in the level of vitamin D3 between first and second children was significant. Mean level of vitamin D was $36.4 \pm 12.3 \mathrm{ng} / \mathrm{ml}$ vs. $49 \pm 13.2 \mathrm{ng} / \mathrm{ml}$ in first and second infants, respectively $(P$ value $=0.011)($ Fig. 1). Although, there was a significant difference between vitamin $D$ and rank of children, but there was not any significant difference between first and second children in each group of vitamin D levels ( $P$ value: Sufficient $=0.28$, Deficient $=0.19$ ).

There was not any significant difference and relation between vitamin D3 and some other variables such as season of birth (P value $=0.091)(F i g .2)$, gestational age $(r=-0.214$, $P$ value $=0.21)$, age of neonates $(P$ 
value $=0.052)$. In return head circumference $(r=-0.404, P$ value $=0.014)$ and age of mothers $(r=0.344, P$ value $=0.04)$ correlated with vitamin D level.

\section{Discussion}

In the present study, we evaluated level of serum vitamin $D$ and the different range of it in both neonates and mothers. More than $50 \%$ of mothers and infants were in sufficient group.

Prevalence of vitamin D deficiency is high in developing countries as well as its resurgence in developed countries. It is related to several lifestyles and environmental factors such as insufficient exposure to sunlight, increased breastfeeding among women with dark skin, and declining numbers of doctors typically feeding vitamin D supplements to infants $(13,14)$.

Classically, nutritional rickets presents after 6 month of age. According to two studies with a relatively high patient population, the youngest patients were 5 and 4 months old and the mean age at diagnosis was 14.6 and 20.2 months, respectively (15-19).

Exclusively breastfed infants according to recent guidelines from the American Academy of Pediatrics should intake at least 5 micrograms of vitamin D for at least the first 2 months. In addition, they recommend vitamin D supplementation to all infants (20).

According to one study deficient infants combined high-dose maternal vitamin D3 supplementation (2000 IU once daily or 60000 IU once monthly) and 400 IU once daily. So that vitamin D status improve significantly (8).

Most of the neonates of our study born in autumn and winter. These seasons have inadequate sunshine and people intake less vitamin D. We found that there is not any significant relation between vitamin $D$ level of mothers and neonates and season of birth. The importance of sunshine discussed in previous other reports $(5,21)$.

The correlation between the level of vitamin D in infants and mothers is not significant. As long as the growth rate is high in the first 2 years, supplementation should be recommended for all children under 2 years of age. Similarly, adolescence is also a period of fast growth (22).

Un-supplemented infants had low serum 25(OH) D3 levels, particularly if exclusively breast-fed and during winter $(23,24)$.

In addition, significant relationship was not shown between gender and vitamin D and the mean level in boys was higher than girls.

Clara Crescioli et al showed that there are some factors that is affecting vitamin $D$ action which name is gender-dependent factors. There is sex-related differences of "absolute" vitamin D levels so these factors seems to be critical (25). 
Other variables in our study for instance gestational age and age of neonates were not correlated with vitamin D. But other significant correlation was between vitamin D and head circumference reversely; and also age of mothers directly.

Low 25-hydroxyvitamin D3 (25(OH) vitamin D) or calcidiol, levels according to Different studies have some relation with low birth weight and gestational age (26).

High dose vitamin D supplementation have some beneficial and adverse outcomes during pregnancy. A large randomized controlled trial in 2004 showed maternal and fetal outcomes with supplementation high dose vitamin D (4000 IU/day) starting before 16 weeks' gestation. Either in the mother or the fetus, they didn't reach to any association with adverse events at this dose (27).

There appear to be fewer pregnancy-associated comorbidities with serum vitamin $D$ concentrations > $40 \mathrm{ng} / \mathrm{ml}$ (28) highlighting the importance of achieving adequate serum concentrations of vitamin $\mathrm{D}$.

Vitamin D3 supplementation according to Doria $\mathrm{K}$ Thiele et al study is an effective intervention from prenatal to postpartum. This supplementation can increase status of vitamin $D$ in mothers and promote this status in exclusively breastfed infants and newborns (29).

The neonatal vitD status at birth and at two weeks of age had a strong, direct and significant relationship with maternal vitD at the time of delivery, but the neonatal P, $\mathrm{Ca}$ and Alk level had a direct and significant correlation with maternal P, Ca and Alk level only at the time of birth, and unlike vitD, this relationship decreased significantly after two weeks (30).

During childhood and adulthood, vitamin D is an important element of bone health. Recently, studies showed that vitamin $D$ develop other non-skeletal diseases which is important to improve the proper condition of vitamin D. Vitamin D supplementation should be recommended in all infants independently of the type of diet and should subsequently be individualized in terms of regimen and duration based on the presence of risk factors for vitamin D deficiency (22).

This study has limitations that need to be considered when interpreting results. We conducted a singlecenter observational study, and thus, as with any observational study, the potential remains for residual confounding.

\section{Conclusion}

In summary, we demonstrated that most of the infants had vitamin D sufficiency at the age of 1 year by using vitamin D supplement and it is recommended to continue vitamin D3 supplementation consumption because of its benefits for child growth. Also vitamin D sufficiency in mother could not guarantee good level of vitamin $D$ in their infants. So supplementation is needed from the first day of neonate life. 


\section{Declarations}

\section{Informed consent:}

Written informed consent was obtained from the parents of the patients for publication of this study.

\section{Ethics approval:}

Ethical approval for this study was obtained from Iran University of Medical Sciences Ethics Committee (ID: IR.IUMS.REC.1397.864).

\section{Consent for publication:}

The consent for publication of personal detailed data was obtained from parents.

\section{Availability of data and material:}

The datasets used during the current retrospective study are available in the text of manuscript.

\section{Conflict interests:}

The authors declare no conflict of interest in preparing this retrospective study.

\section{Funding:}

This research was supported by grant No 1397-2-15-12404 from Student Research committee, School of Medicine, Iran University of Medical Science.

\section{Acknowledgement:}

We thank the Student Research committee, School of Medicine, Iran University of Medical Science.

\section{Authors' contributions:}

$\mathrm{KN}$ and $\mathrm{KM}$ analyzed and interpreted the patient data. $\mathrm{AD}, \mathrm{SM}$ and $\mathrm{AM}$ performed follow up the patient and were major contributors in writing the manuscript. All of authors read and approved the final manuscript.

\section{References}

1. Blann A. An update on vitamin D deficiency and at risk groups. Journal of family health. 2015;25(3):16-9.

2. Mazouri A, Khosravi N, Bordbar A, Khalesi N, Saboute M, Taherifard P, et al. Does Adding Intravenous Phosphorus to Parenteral Nutrition Has Any Effects on Calcium and Phosphorus Metabolism and Bone Mineral Content in Preterm Neonates? Acta medica Iranica. 2017;55(6):395-8. 
3. Wicklow B, Gallo S, Majnemer A, Vanstone C, Comeau K, Jones G, et al. Impact of Vitamin D Supplementation on Gross Motor Development of Healthy Term Infants: A Randomized DoseResponse Trial. Physical \& occupational therapy in pediatrics. 2016;36(3):330-42.

4. Atiq M, Suria A, Nizami SQ, Ahmed I. Vitamin D status of breastfed Pakistani infants. Acta paediatrica (Oslo, Norway : 1992). 1998;87(7):737-40.

5. Dawodu A, Agarwal M, Hossain M, Kochiyil J, Zayed R. Hypovitaminosis D and vitamin D deficiency in exclusively breast-feeding infants and their mothers in summer: a justification for vitamin $D$ supplementation of breast-feeding infants. The Journal of pediatrics. 2003;142(2):169-73.

6. Hatun S, Ozkan B, Orbak Z, Doneray H, Cizmecioglu F, Toprak D, et al. Vitamin D deficiency in early infancy. The Journal of nutrition. 2005;135(2):279-82.

7. Clancy N, Onwuneme C, Carroll A, McCarthy R, McKenna MJ, Murphy N, et al. Vitamin D and neonatal immune function. The journal of maternal-fetal \& neonatal medicine : the official journal of the European Association of Perinatal Medicine, the Federation of Asia and Oceania Perinatal Societies, the International Society of Perinatal Obstet. 2013;26(7):639-46.

8. Saadi HF, Dawodu A, Afandi B, Zayed R, Benedict S, Nagelkerke N, et al. Effect of combined maternal and infant vitamin $D$ supplementation on vitamin $D$ status of exclusively breastfed infants. Maternal \& child nutrition. 2009;5(1):25-32.

9. Manson JE, Brannon PM, Rosen CJ, Taylor CL. Vitamin D Deficiency - Is There Really a Pandemic? The New England journal of medicine. 2016;375(19):1817-20.

10. Trilok-Kumar G, Kaur M, Rehman AM, Arora H, Rajput MM, Chugh R, et al. Effects of vitamin D supplementation in infancy on growth, bone parameters, body composition and gross motor development at age 3-6 years: follow-up of a randomized controlled trial. International journal of epidemiology. 2015;44(3):894-905.

11. Koo W, Walyat N. Vitamin D and skeletal growth and development. Current osteoporosis reports. 2013;11(3):188-93.

12. Katrinaki M, Kampa M, Margioris A, Castanas E, Malliaraki N. Vitamin D levels in a large Mediterranean cohort: reconsidering normal cut-off values. Hormones (Athens, Greece). 2016;15(2):205-23.

13. Calikoglu AS, Davenport ML. Prophylactic vitamin D supplementation. Endocrine development. 2003;6:233-58.

14. Davenport ML, Uckun A, Calikoglu AS. Pediatrician patterns of prescribing vitamin supplementation for infants: do they contribute to rickets? Pediatrics. 2004;113(1 Pt 1):179-80.

15. DeLucia MC, Mitnick ME, Carpenter TO. Nutritional rickets with normal circulating 25-hydroxyvitamin D: a call for reexamining the role of dietary calcium intake in North American infants. The Journal of clinical endocrinology and metabolism. 2003;88(8):3539-45.

16. Kreiter SR, Schwartz RP, Kirkman HN, Jr., Charlton PA, Calikoglu AS, Davenport ML. Nutritional rickets in African American breast-fed infants. The Journal of pediatrics. 2000;137(2):153-7. 
17. Shah M, Salhab N, Patterson D, Seikaly MG. Nutritional rickets still afflict children in north Texas. Texas medicine. 2000;96(6):64-8.

18. Welch TR, Bergstrom WH, Tsang RC. Vitamin D-deficient rickets: the reemergence of a onceconquered disease. The Journal of pediatrics. 2000;137(2):143-5.

19. Wright A, Schanler $R$. The resurgence of breastfeeding at the end of the second millennium. The Journal of nutrition. 2001;131(2):421s-5s.

20. Gartner LM, Greer FR. Prevention of rickets and vitamin D deficiency: new guidelines for vitamin $D$ intake. Pediatrics. 2003;111(4 Pt 1):908-10.

21. Saadi HF, Nagelkerke N, Benedict S, Qazaq HS, Zilahi E, Mohamadiyeh MK, et al. Predictors and relationships of serum 25 hydroxyvitamin $D$ concentration with bone turnover markers, bone mineral density, and vitamin D receptor genotype in Emirati women. Bone. 2006;39(5):1136-43.

22. Saggese G, Vierucci F, Boot AM, Czech-Kowalska J, Weber G, Camargo CA, Jr., et al. Vitamin D in childhood and adolescence: an expert position statement. European journal of pediatrics. 2015;174(5):565-76.

23. Merewood A, Mehta SD, Grossman X, Chen TC, Mathieu J, Holick MF, et al. Vitamin D status among 4-month-old infants in New England: a prospective cohort study. Journal of human lactation : official journal of International Lactation Consultant Association. 2012;28(2):159-66.

24. Vanstone MB, Oberfield SE, Shader L, Ardeshirpour L, Carpenter TO. Hypercalcemia in children receiving pharmacologic doses of vitamin D. Pediatrics. 2012;129(4):e1060-3.

25. Crescioli C, Minisola S. Vitamin D : Autoimmunity and Gender. Current medicinal chemistry. 2017;24(24):2671-86.

26. Saboute M, Yavar R, Kashaki M, Khaledi FK, Khalesi N, Rohani F. Investigation of association between maternal $25-\mathrm{OH}$ vitamin D serum levels and neonatal early onset sepsis in newborns by evaluating key factors. Lipids in health and disease. 2019;18(1):153.

27. Hollis BW, Johnson D, Hulsey TC, Ebeling M, Wagner CL. Vitamin D supplementation during pregnancy: double-blind, randomized clinical trial of safety and effectiveness. Journal of bone and mineral research : the official journal of the American Society for Bone and Mineral Research. 2011;26(10):2341-57.

28. Wagner CL, Baggerly C, McDonnell S, Baggerly KA, French CB, Baggerly L, et al. Post-hoc analysis of vitamin $D$ status and reduced risk of preterm birth in two vitamin $D$ pregnancy cohorts compared with South Carolina March of Dimes 2009-2011 rates. The Journal of steroid biochemistry and molecular biology. 2016;155(Pt B):245-51.

29. Thiele DK, Ralph J, El-Masri M, Anderson CM. Vitamin D3 Supplementation During Pregnancy and Lactation Improves Vitamin D Status of the Mother-Infant Dyad. Journal of obstetric, gynecologic, and neonatal nursing : JOGNN. 2017;46(1):135-47.

30. Kashaki M, Alipour R, Saboute M, editors. Changes in Vitamin D Status during the First Two Weeks of Life in Preterm Infants on TPN : A Cross Sectional Study2019. 


\section{Tables}

Table 1.

Main characteristics of infants and mothers

\begin{tabular}{|c|c|c|c|c|c|}
\hline & \multicolumn{2}{|c|}{ Variables } & Mean \pm SD & Minimum & Maximum \\
\hline \multicolumn{6}{|l|}{ Infants } \\
\hline & \multicolumn{2}{|c|}{ Vitamin D3(ng/ml) } & $40.99 \pm 13.86$ & 12 & 81 \\
\hline & \multicolumn{2}{|c|}{ Age (month) } & $15.79 \pm 2.788$ & 12 & 23 \\
\hline & \multirow[t]{2}{*}{ Gender } & Boy & $39.55 \pm 3.79$ & 12 & 51 \\
\hline & & Girl & $35.32 \pm 3.67$ & 13.4 & 50 \\
\hline & \multicolumn{2}{|c|}{ Head circumference (centimeter) } & $33.694 \pm 2.6157$ & 26.5 & 38.0 \\
\hline & \multicolumn{2}{|c|}{ Weight (gram) } & $2871.54 \pm 867.678$ & 1050 & 4800 \\
\hline & \multicolumn{2}{|c|}{ Gestational age (month) } & $36.80 \pm 2.990$ & 29 & 40 \\
\hline \multicolumn{6}{|l|}{ Mothers } \\
\hline & \multicolumn{2}{|c|}{ Vitamin D3(ng/ml) } & $31.39 \pm 13.14$ & 10 & 54 \\
\hline & \multicolumn{2}{|c|}{ Age (year) } & $33 \pm 3$ & 21 & 40 \\
\hline
\end{tabular}

Table 2.

Different levels of serum vitamin D3 in infants and mothers

\begin{tabular}{|c|c|c|c|}
\hline & Vitamin D Range & Frequency & Percent \\
\hline \multicolumn{4}{|l|}{ Infants } \\
\hline & Deficient $(<30 \mathrm{ng} / \mathrm{ml})$ & 11 & 16.7 \\
\hline & Sufficient ( $\geq 30 \mathrm{ng} / \mathrm{ml})$ & 57 & 83.3 \\
\hline & Total & 68 & 100 \\
\hline \multicolumn{4}{|l|}{ Mothers } \\
\hline & Deficient $(<30 \mathrm{ng} / \mathrm{ml})$ & 26 & 37.9 \\
\hline & Sufficient $(\geq 30 \mathrm{ng} / \mathrm{ml})$ & 42 & 62.1 \\
\hline & Total & 68 & 100 \\
\hline
\end{tabular}

\section{Figures}




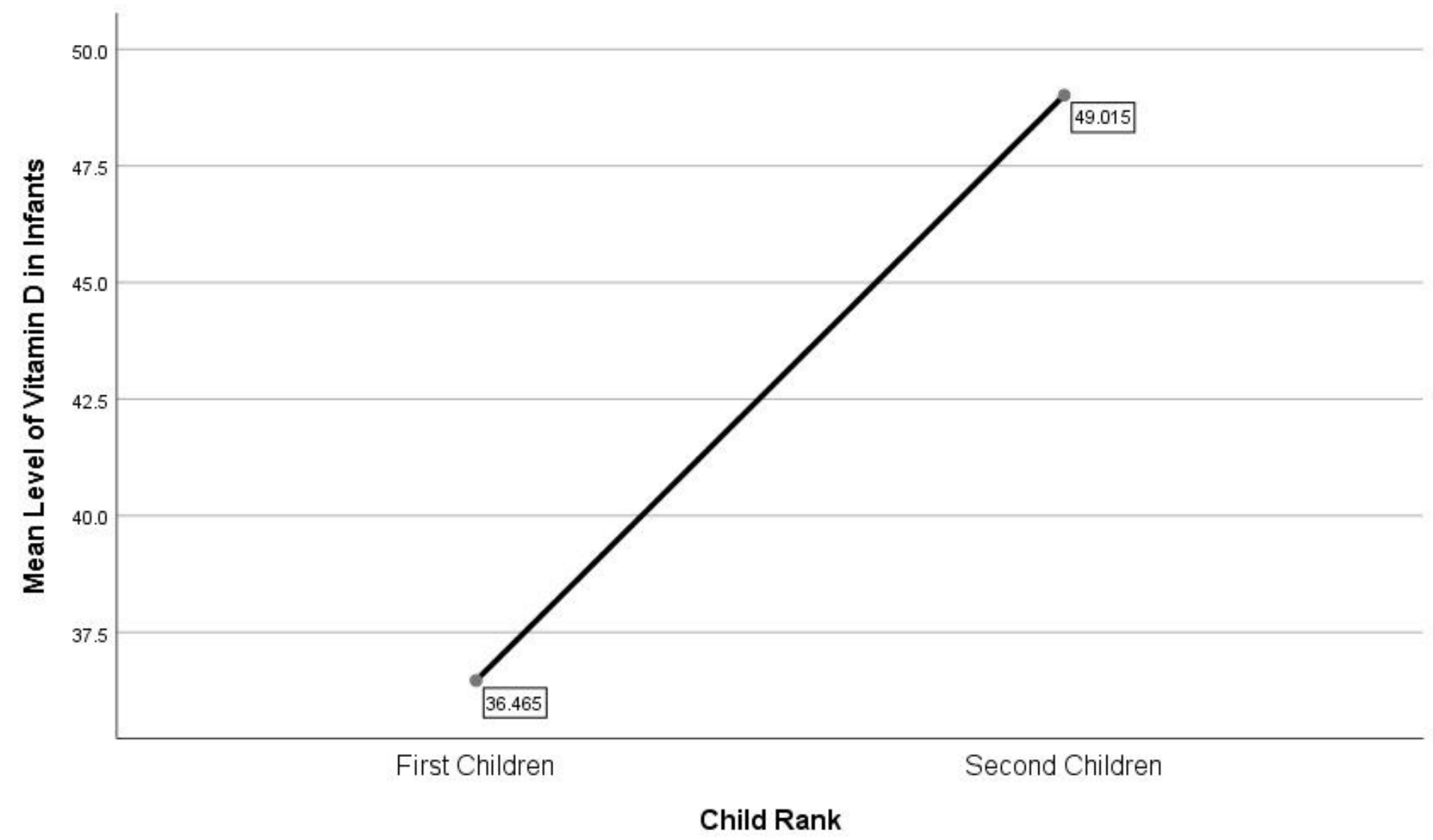

Figure 1

Comparison the mean level of serum vitamin $D$ in first and Second children Level of vitamin $D$ in second children was significantly higher than first children ( $P$ value $=0.011)$. 


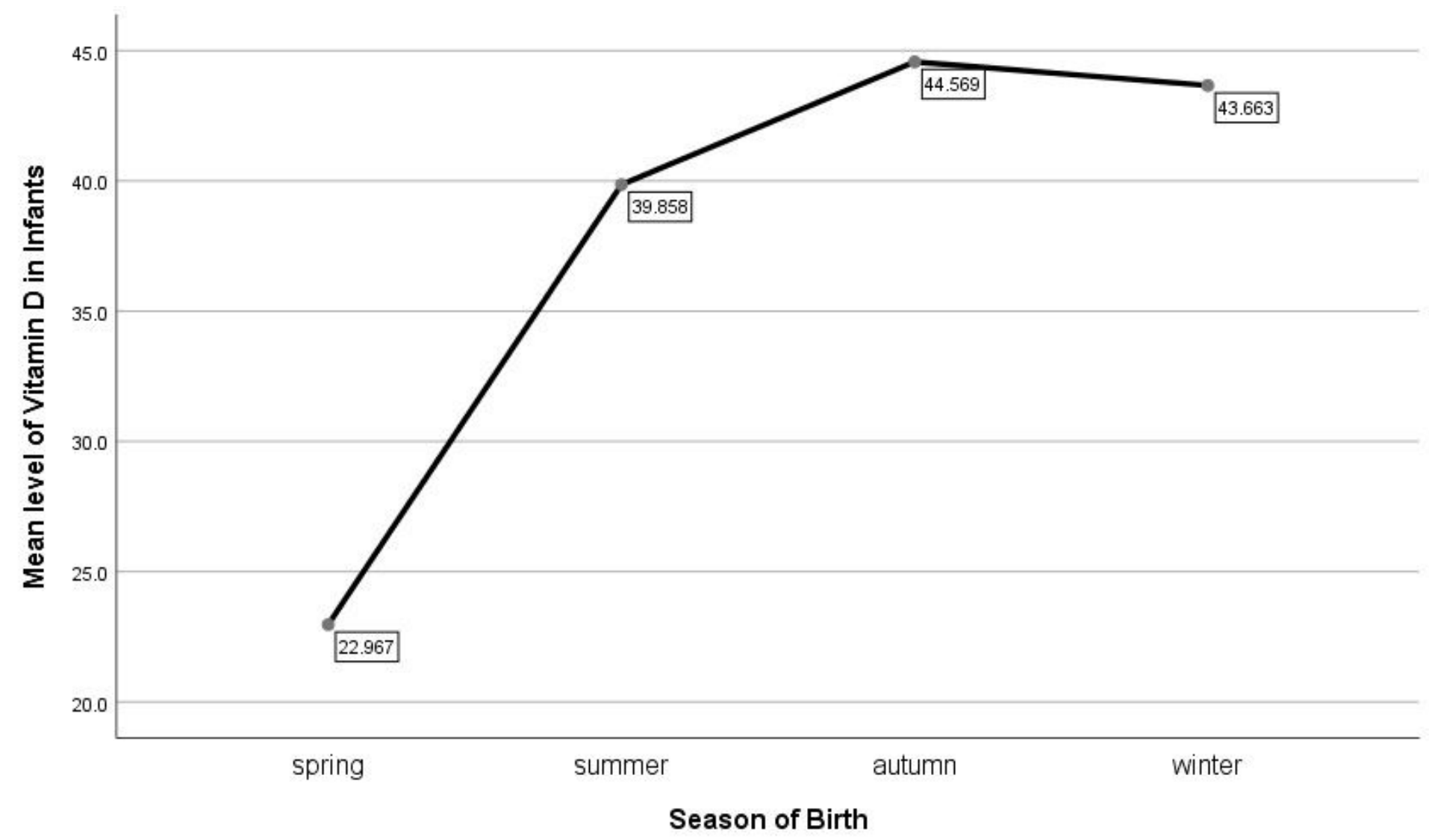

Figure 2

Mean level of serum vitamin D of neonates in different seasons

\section{Supplementary Files}

This is a list of supplementary files associated with this preprint. Click to download.

- references.rar

- references.rar 